\title{
Pengaruh prenatal yoga terhadap lama kala II persalinan dan kejadian robekan perinium
}

\author{
Ni Wayan Noviani, ${ }^{1 *}$ Ni Wayan Sukma Adnyani ${ }^{2}$ \\ 1, 2 Politeknik Kesehatan Kartini Bali, Denpasar - Indonesia
}

\begin{abstract}
Labor is assumed to be a painful and tense process, but labor can be passed with a sense of security and comfort without trauma. Yoga is considered one of the alternative therapies to prepare pregnant women physically, mentally, and spiritually to face the birth process and prevent perineal rupture. This study aims to determine prenatal yoga's effect on the duration of the second stage of labor and the incidence of perineal tears at the Bumi Sehat Foundation Ubud Bali in 2018. The study was conducted by analytic design with a prospective study approach. The research subjects used 50 pregnant women who gave birth at the Bumi Sehat Foundation. The study used Mann-Whitney and chi-square. Based on the data analysis of the influence between Prenatal yoga on the duration of the second stage of analysis using Mann-Whitney $p$-value $<0.005$ which means that there is an influence between prenatal yoga on the second time while based on Chi-square data analysis $p$-value 0.012 where $p$-value $<0,005$ which means that there is an influence between Prenatal yoga and perineum tear. It can be concluded that prenatal yoga is effective in helping pregnancy and childbirth are minimally traumatic in women.
\end{abstract}

Keywords: prenatal yoga; second stage of labor; perineal tear

Persalinan diasumsikan sebagai proses yang menyakitkan dan menegangkan namun, persalinan dapat dilalui dengan rasa aman dan nyaman tanpa trauma. Yoga dianggap sebagai salah satu terapi alternatif untuk mempersiapkan ibu hamil secara fisik, mental dan spiritual dalam menghadapi proses kelahiran serta untuk mencegah ruptur perineum. Penelitian ini bertujuan untuk mengetahui pengaruh prenatal yoga terhadap lama kala II persalinan dan kejadian robekan perineum di Yayasan Bumi Sehat Ubud Bali tahun 2018. Penelitian dilakukan dengan rancangan analitik dengan pendekatan prospective study. Subjek penelitian menggunakan 50 ibu hamil yang bersalin di Yayasan Bumi Sehat. Analisis data yang digunakan adalah Mann-whitney dan chi-square. Berdasarkan analisis data pengaruh antara Prenatal yoga terhadap lama kala II analisa menggunakan Mann-whitney diperoleh nilai $p$-value $<0,005$ yang berarti bahwa ada pengaruh antara Prenatal yoga terhadap lama kala II sedangkan berdasarkan analisis data dengan menggunakan Chi-squre diperoleh p-value 0, 012 dimana p-value < 0, 005 yang berarti bahwa ada pengaruh antara prenatal yoga terhadap robekan perinium. Sehingga dapat disimpulkan prenatal yoga efektif dalam membantu kehamilan dan persalinan yang minim trauma pada seorang wanita.

Kata Kunci: prenatal yoga; lama kala II; robekan perinium 


\section{Pendahuluan}

Persalinan diasumsikan sebagai proses yang menyakitkan dan menegangkan, namun persalinan dapat dilalui dengan rasa aman dan nyaman tanpa trauma. Menurut (Jannah, 2015) persalinan adalah proses pengeluaran hasil konsepsi yang dapat hidup dari dalam uterus ke dunia luar. Beberapa faktor yang mempengaruhi persalinan yaitu faktor power, faktor passenger, faktor passage, dan faktor psyche.

Menurut (Campion \& Bascom, 2011) kejadian ruptur perineum pada ibu bersalin di dunia pada tahun 2015 terdapat 2,7 juta kasus, dimana angka ini diperkirakan akan mencapai 6,3 juta pada tahun 2050. Di Benua Asia $50 \%$ ibu bersalin mengalami ruptur perineum (WHO, 2015). Robekan perineum atau trauma jalan lahir di Indonesia terjadi pada golongan umur 25-30 tahun yaitu $24 \%$, dan pada ibu umur 32-39 tahun sebesar $62 \%$.

Faktor yang dapat menunjang proses kehamilan, kelahiran dan meminimalkan kejadian laserasi perineum yaitu kelenturan jalan lahir (Pujianti et al., 2018). Ibu hamil dianjurkan melakukan aktifitas fisik seperti olahraga ringan selama hamil (Mediarti et al., 2014). Yoga dianggap sebagai salah satu terapi alternatif untuk mempersiapkan ibu hamil secara fisik, mental dan spiritual dalam menghadapi proses kelahiran serta untuk mencegah ruptur perineum (Shindu, 2014).

Kesehatan mental termasuk kecemasan kehamilan terbukti dapat dikurangi atau dihilangkan melalui latihan fisik (physical excersice) dan hal ini perlu dipromosikan (Hall et al., 2016). Salah satu latihan fisik yang direkomendasikan adalah yoga karena biaya rendah, mudah untuk dilakukan dan sangat bermanfaat untuk kebugaran fisik dan psikologi (Shiraishi \& Bezerra, 2016)

Yayasan Bumi Sehat merupakan salah satu klinik kesehatan yang menyelenggarakan program persalinan Gentle Birth yaitu persalinan yang aman, nyaman dan bebas trauma. Kita ketahui Hypnobirthing adalah metode persalinan yang memberdayakan ibu dan bayi agar bisa lahir sehat, selamat dan minim trauma (Mahmudah, 2013). Salah Salah satu bagian dari Hypnobirthing adalah prenatal yoga yang merupakan unggulan Yayasan Bumi Sehat. Kegiatan ini yaitu dilakukan setiap minggu untuk membantu ibu hamil dalam mempersiapkan kehamilan dan persalinan yang menyenangkan dan minim trauma.

Adapun tujuan penelitian ini untuk mengetahui pengaruh Prenatal Yoga terhadap lama Kala II Persalinan dan kejadian robekan perineum di Yayasan Bumi Sehat Ubud Bali, sehingga diharapkan penelitian ini dapat diterapkan atau menjadi alternatif bagi tenaga kesehatan dalam memberikan asuhan kebidanan yang berkualitas, sesuai evidence base dan minim trauma bagi ibu hamil.

\section{Metode}

Rancangan penelitian ini adalah analitik dengan pendekatan prospective study. Penelitian ini dilaksanakan di Yayasan Bumi Sehat, Nyuh Kuning, Ubud. Penelitian dilakukan pada bulan Agutus s.d. Oktober 2018 dengan membutuhkan waktu selama 3 bulan.

Sampel dalam penelitian ini adalah seluruh ibu yang bersalin di Yayasan Bumi Sehat yang berjumlah 50 orang dengan kriteria inklusi: Ibu 
bersalin Primi dengan riwayat melakukan yoga prenatal minimal 2 kali seminggu pada TM III (Teratur $\geq 6$ kali, tidak teratur $<6$ kali), ibu bersalin tanpa komplikasi dan bersedia menjadi responden. Pengambilan sampel menggunakan teknik Non Probability Samping dengan jenis Purposive Sampling. Data dikumpulkan dengan metode observasi langsung pada Kala II dengan menggunakan lembar partograph.dan lembar kuesioner untuk data karakteristik pasien. Variabel dalam penelitian ini dibagi dua, variabel independent; lama kala II persalinan dan robekan perinium dan variabel dependent adalah prenatal yoga. Data dianalisis secara deskriptif dan bivariate dengan uji Mann Whitney dan Chi Square. (Notoadmodjo, 1997) Penelitian ini telah dinyatakan laik etik oleh Komisi Etik Penelitian Fakultas Kedokteran Universitas Udayana/ Rumah Sakit Umum Pusat Sanglah Denpasar dengan nomor 2931/UN14.2.2.VII.14/LP/2018.

\section{Hasil dan Pembahasan}

Hasil analisa secara deskriptif pada karakteristik responden di Yayasan Bumi Sehat Bali dapat dilihat pada Tabel 1. Berdasarkan Tabel 1 dapat diketahui bahwa hampir setengahnya yaitu 22 responden (44\%) memiliki kategori pendidikan tinggi, hampir seluruhnya yaitu 45 (90\%) berada pada usia reproduktif antara 20 sampai dengan 35 tahun, sebagian besar yaitu 36 responden (72\%) memperoleh informasi melalui tenaga kesehatan, dan sebagian besar yaitu 29 responden (58\%) merupakan kategori multigravida.

Berdasarkan hasil analisa data Tabel 2, nilai rata-rata lama kala II tertinggi didapatkan 58 menit dan nilai terendah 1 menit. Nilai mean diperoleh 21, 48 menit dengan nilai median 19,50 menit dengan standar deviasi 17,07 menit.

Tabel 1. Distribusi frekuensi Karakteristik Responden di Yayasan Bumi Sehat

\begin{tabular}{lcc}
\hline \multicolumn{1}{c}{ Karakteristik } & $\mathrm{n}$ & $\%$ \\
\hline Pendidikan & 8 & 16 \\
Pendidikan Dasar (SD/SMP) & 20 & 40 \\
Pendidikan Menengah (SMA) & 22 & 44 \\
Pendidikan Tinggi (PT) & & \\
Usia & 1 & 2 \\
<20 tahun & 45 & 90 \\
20-35tahun & 4 & 8 \\
$>35$ tahun & & \\
Sumber informasi & 3 & 6 \\
Media Massa & 36 & 72 \\
Tenaga Kesehatan & 11 & 22 \\
Orang terdekat & & \\
Gravida & 21 & 42 \\
Primigravida & 29 & 58 \\
Multigravida & 0 & 0 \\
Grande Multigravida & & \\
\hline
\end{tabular}


Tabel 2. Statistik Deskriptif Lama Kala II pada Responden di Yayasan Bumi Sehat Tahun 2018

\begin{tabular}{llc}
\hline No. & Statistik Deskriptif & Lama Kala II (menit) \\
\hline 1. & Mean & 21,48 \\
2. & Median & 19,50 \\
3. & Standar Deviasi & 17,07 \\
\hline
\end{tabular}

Tabel 3. Distribusi Frekuensi Pengaruh Prenatal Yoga terhadap Derajat Robekan Perinium di Yayasan Bumi Sehat

\begin{tabular}{|c|c|c|c|c|c|c|c|c|}
\hline \multirow{3}{*}{$\begin{array}{c}\text { Prenatal } \\
\text { Yoga }\end{array}$} & \multicolumn{6}{|c|}{ Robekan Perinium } & \multirow{2}{*}{\multicolumn{2}{|c|}{ Total }} \\
\hline & \multicolumn{2}{|c|}{ Tidak ada Robekan } & \multicolumn{2}{|c|}{ Laserasi Grade I } & \multicolumn{2}{|c|}{ Laserasi Grade II } & & \\
\hline & $f$ & $\%$ & $f$ & $\%$ & $f$ & $\%$ & $f$ & $\%$ \\
\hline Tidak Teratur & 3 & 10 & 10 & 33,3 & 17 & 56,7 & 30 & 100 \\
\hline Teratur & 5 & 25 & 12 & 60 & 3 & 15 & 20 & 100 \\
\hline
\end{tabular}

Tabel 4. Distribusi Frekuensi Pengaruh Prenatal Yoga terhadap Derajat Robekan Perinium di Yayasan Bumi Sehat

\begin{tabular}{|c|c|c|c|c|c|c|c|c|}
\hline \multirow{3}{*}{$\begin{array}{l}\text { Prenatal } \\
\text { Yoga }\end{array}$} & \multicolumn{6}{|c|}{ Robekan Perinium } & \multirow{2}{*}{\multicolumn{2}{|c|}{ Total }} \\
\hline & \multicolumn{2}{|c|}{ Tidak ada Robekan } & \multicolumn{2}{|c|}{ Laserasi Grade I } & \multicolumn{2}{|c|}{ Laserasi Grade II } & & \\
\hline & $f$ & $\%$ & $f$ & $\%$ & $f$ & $\%$ & $f$ & $\%$ \\
\hline $\begin{array}{c}\text { Tidak Teratur } \\
\text { (<6 kali) }\end{array}$ & 3 & 10 & 10 & 33,3 & 17 & 56,7 & 30 & 100 \\
\hline $\begin{array}{c}\text { Teratur (> } \\
\text { kali) }\end{array}$ & 5 & 25 & 12 & 60 & 3 & 15 & 20 & 100 \\
\hline
\end{tabular}

Berdasarkan Tabel 3 dapat diinformasikan bahwa dari 30 responden (100\%) yang mengikuti prenatal yoga secara tidak teratur diperoleh sebagian kecil yaitu tiga (10\%) tanpa robekan pada perinium, hampir setengahnya yaitu 10 $(33,3 \%)$ dengan laserasi grade I dan sebagian besar yaitu $17(56,7 \%)$ responden dengan laserasi grade II. Dari total $20(100 \%)$ responden yang melakukan prenatal yoga secara teratur, diperloeh sebagian kecil yaitu lima (25\%) tanpa robekan perinium, sebagian besar yaitu $12(60 \%)$ dengan laserasi grade I dan sebagian kecil yaitu tiga (15\%) dengan laserasi grade II.

Berdasarkan Tabel 4 dapat diinformasikan bahwa dari 30 responden (100\%) yang mengikuti prenatal yoga secara tidak teratur diperoleh sebagian kecil yaitu tiga (10\%) tanpa robekan pada perinium, hampir setengahnya yaitu 10 $(33,3 \%)$ dengan laserasi grade I dan sebagian besar yaitu $17(56,7 \%)$ responden dengan laserasi grade II. Dari total $20(100 \%)$ responden yang melakukan prenatal yoga secara teratur, diperloeh sebagian kecil yaitu lima (25\%) tanpa robekan perinium, sebagian besar yaitu $12(60 \%)$ dengan laserasi grade I dan sebagian kecil yaitu tiga (15\%) dengan laserasi grade II.

Pada Tabel 5, dijelaskan bahwa berdasarkan analisis data dengan menggunakan Mannwhitney diperoleh $p$ vaule $<0,005$ yang berarti bahwa ada pengaruh antara Prenatal yoga terhadap lama kala II. 
Pengaruh prenatal yoga terhadap lama kala II persalinan dan kejadian robekan perinium

Tabel 5. Analisis Pengaruh Prenatal Yoga terhadap Lama Kala II Persalinan di Yayasan Bumi Sehat

\begin{tabular}{lccc}
\hline \multicolumn{1}{c}{ Kelompok } & $\mathrm{n}$ & Mean & $\begin{array}{c}\text { Asymp } \\
\text { Sig (2-tailed) }\end{array}$ \\
\hline Teratur & 30 & 33,43 & 0,000 \\
Tidak teratur & 20 & 13,60 & \\
\hline
\end{tabular}

Tabel 6. Analisis Pengaruh Prenatal Yoga terhadap Robekan Perineum di Yayasan Bumi Sehat

\begin{tabular}{ccc}
\hline Kelompok & $\mathrm{n}$ & $\begin{array}{c}\text { Asymp } \\
\text { Sig (2-tailed) }\end{array}$ \\
\hline Pearson chi-square & 8,835 & 0,012 \\
\hline
\end{tabular}

Pada Tabel 6, dijelaskan bahwa berdasarkan analisis data dengan menggunakan chi-squre diperoleh $p$-value 0,012 dimana $p$-value $<0,005$ yang berarti bahwa ada pengaruh antara Prenatal yoga terhadap robekan perinium

\section{Hubungan Prenatal Yoga terhadap Lama Kala II Persalinan}

Berdasarkan teori yang dikemukakan oleh (Cunningham, 2013) menyatakan bahwa Kala II lama adalah persalinan yang sudah dipimpin mengejan pada primigravida dibatasi 2 jam dan diperpanjang sampai 3 jam apabila digunakan analgesia regional, sedangkan pada multigravida dibatasi 1 jam dan diperpanjang sampai 2 jam apabila digunakan analgesia regional.

Berdasarkan hasil analisis data yaitu nilai mean diperoleh 21,48 menit dan nilai median 19 , 50 menit maka prenatal yoga efektif dalam memperpendek lama kala II persalinan. Sejalan dengan teori yang dikemukan oleh (Curtis et al., 2012) menyatakan bahwa prenatal yoga dapat menurunkan stres, meningkatkan kualitas hidup, self efficacy pada persalinan, hubungan interpersonal, fungsi sistem saraf otonom, memberi rasa nyaman, mengurangi atau menurunkan nyeri persalinan dan memperpendek durasi persalinan.

Hasil penelitian lain yang dilakukan oleh (Putri, 2019) menyatakan bahwa prenatal yoga memiliki korelasi yang kuat dengan lama proses persalinan kala II. Dimana dengan melakukan prenatal yoga maka otot-otot dinding perut, diafragma, otototot persendian dan otot perineum ibu semakin kuat dan elastis. Penelitian serupa yang juga dilakukan oleh (Yohanna, 2018) menyatakan ada hubungan prenatal yoga terhadap proses persalinan kala II $(p=0,003)$. Selain itu dengan melakukan prenatal yoga juga mempengaruhi ketegangan ibu karena ibu telah terbiasa untuk dapat berkonsentrasi secara penuh dan mendapatkan ketenangan saat prenatal yoga, sehingga saat persalinan ibu juga akan merasakan tenang dan nyaman (Rusmita, 2015).

\section{Hubungan Prenatal Yoga terhadap Robekan Perinium}

Berdasarkan analisis data diperoleh data responden yang tidak teratur melakukan yoga yaitu sebagian besar yaitu $17(56,7 \%)$ responden 
dengan laserasi grade II. Data responden yang melakukan prenatal yoga secara teratur, diperoleh sebagian besar yaitu 12 (60\%) dengan laserasi grade I yang artinya tidak diperlukan tindakan penjahitan.

Menurut (Siringoringo, 2018) menyatakan bahwa robekan perineum spontan terjadi karena ketegangan di daerah vagina pada saat persalinan, dan adanyan perbedaan ukuran antara jalan lahir dan janin serta psikologis ibu dalam menghadapi proses persalinan. Paritas juga memiliki pengaruh terhadap Robekan perineum (Hutomo, 2009). Tanpa penatalaksanaan yang tepat, akan menyebabkan rasa tidak nyaman, perdarahan, termasuk kematian pada ibu nifas (Irawati, 2017).

Hasil penelitian ini sejalan dengan hasil penelitian yang dilakukan oleh (Setyowati et al., 2017) menyatakan bahwa secara statistik ( $p=$ 0.000 ) prenatal yoga efektif dalam mencegah terjadinya robekan perineum. Hasil penelitian menunjukkan sebagian besar yaitu 14 (56\%) responden mengalami robekan perineum grade I.

Berdasarkan analisis data dengan menggunakan menggunakan Mann-whitney diperoleh pada kelompok teratur $(\mathrm{N}=30)$ dan tidak teratur $(\mathrm{N}=20)$ melakuakn prenatal yoga $\mathrm{p}$ vaule $<0,005$ yang berarti bahwa ada pengaruh antara Prenatal yoga terhadap lama kala II sedangkan chi-squre diperoleh $p$-value sebesar 0,012 dimana $p$-value $<0,005$ yang berarti bahwa ada pengaruh Prenatal yoga terhadap robekan perinium.

Hasil penelitian ini sejalan dengan penelitian (Khalajzadeh et al., 2012; Newham et al., 2014) mengungkapkan bahwa ada prenatal yoga me- miliki efek yang signifikan terhadap lama kala II persalinan dan robekan perineum dan prenatal yoga dapat memperkuat otot-otot panggul dan perut untuk memfasilitasi persalinan. Hasil penelitian lain yang dilakukan oleh (Rahmawati et al., 2016) yaitu mengungkapkan bahwa lamanya persalinan kala II untuk ibu yang melakukan yoga lebih pendek daripada mereka yang tidak melakukan yoga.

Jadi, hasil penelitian ini dapat disimpulkan bahwa ada pengaruh prenatal yoga terhadap lama kala II persalinan dan robekan perineum. Semakin teratur ibu melakukan yoga maka semakin pendek durasi kala II persalinan.

\section{Kesimpulan}

Hasil penelitian ini menunjukkan bahwa ada pengaruh prenatal yoga terhadap lama kala II persalinan dilihat dari nilai mean diperoleh 21,48 menit dan nilai median 19,50 menit maka prenatal yoga efektif dalam memperpendek lama kala II persalinan. Serta ada pengaruh prenatal yoga terhadap robekan perineum dilihat dari analisis data diperoleh sebagian besar yaitu $12(60 \%)$ dengan laserasi grade I yang artinya tidak diperlukan tindakan penjahitan.[]

\section{Daftar Pustaka}

Campion, C., \& Bascom, B. (2011). Obstetri Williams Volume I. Jakarta: EGC.

Cunningham, C. (2013). Obstetri Williams. Jakarta: EGC.

Curtis, K., Weinrib, A., \& Katz, J. (2012). Systematic review of Yoga for pregnant women: Current status and future directions. Evidence-Based Complementary and Alternative Medicine, 
2012, 1-13. https://doi.org/10.1155/2012/ 715942

Hall, H. G., Beattie, J., Lau, R., East, C., \& Anne Biro, M. (2016). Mindfulness and perinatal mental health: A systematic review. Women and Birth, 29(1), 62-71. https://doi.org/10.1016/ j.wombi.2015.08.006

Hutomo, C. S. (2009). Hubungan antara paritas dengan kejadian ruptur perinium spontan di RSUD Kota Surakarta. Universitas Sebelas Maret Surakarta.

Irawati, D. (2017). Faktor yang berhubungan dengan ruptur perineum di Puskesmas Puri Kabupaten Mojokerto.

Jannah, N. (2015). Konsep dokumentasi kebidanan. Yogyakarta: Ar'ruz Media.

Khalajzadeh, M., Shojaei, M., \& Mirfaizi, M. (2012). The effect of yoga on anxiety among pregnant women in second and third trimester of pregnancy. European Journal of Sports and Exercise Science, 1(3), 85-89.

Mahmudah, S. (2013). Pengaruh pemberian hypnobirthing dengan lama persalinan kala I fase aktif pada ibu bersalin di BPS Prita Yusita Mangunsari Salatiga. STIKES Ngudi Waluyo Semarang.

Mediarti, D., Sulaiman, S., Rosnani, R., \& Jawiah, J. (2014). Pengaruh yoga antenatal terhadap pengurangan keluhan ibu hamil trimester III. Jurnal Kedokteran Dan Kesehatan, 1(1), 4753.

Newham, J. J., Wittkowski, A., Hurley, J., Aplin, J. D., \& Westwood, M. (2014). Effects of antenatal yoga on maternal anxiety and depression: A randomized controlled trial. Depression and Anxiety, 31(8), 631-640. https://doi.org/ $10.1002 /$ da. 22268
Notoadmodjo, S. (1997). Ilmu kesehatan masyarakat. Jakarta: Rineka Cipta.

Pujianti, R. P., Apriastuti, D. A., \& Sulistiani, A. (2018). Hubungan frekuensi senam yoga dengan lama persalinan kala I fase aktif. Jurnal Kebidanan, 10(2), 193-205. https://doi.org/ 10.35872/jurkeb.v10i02.292

Putri, R. D. (2019). Yoga prenatal trimester III dapat mempercepat lama kala II persalinan pada ibu primigravida. Jurnal Kebidanan Malahayati, 5(3), 292-298. https://doi.org/ 10.33024/jkm.v5i3.1441

Rahmawati, N. A., Sutaryono, S., \& Lestari, S. (2016). Hubungan senam hamil terhadap lamanya proses persalinan pada ibu bersalin di wilayah kerja Puskesmas Bayat Klaten. Involusi Jurnal Ilmu Kebidanan, 6(11), 29-37.

Rusmita, E. (2015). Pengaruh senam hamil yoga terhadap kesiapan ibu hamil menghadapi persalinan di RSIA Limijati Bandung. Jurnal Keperawatan BSI, 3(2), 80-86. https: //doi.org/10.31311/.v3i2.155

Setyowati, A., Suhartono, S., Ngadiyono, N., Endang Pujiastuti, R. S., \& Dyah, D. (2017). Effect of yoga on duration of the second stage of labor and perineal rupture in primigravida mothers. Belitung Nursing Journal, 3(6), 702-706. https://doi.org/10.33546/bnj.295

Shindu, P. (2014). Yoga untuk Kehamilan: Sehat, Bahagia, dan Penuh Makna. Bandung: Qanita.

Shiraishi, J. C., \& Bezerra, L. M. A. (2016). Effects of yoga practice on muscular endurance in young women. Complementary Therapies in Clinical Practice, 22(22), 69-73. https: //doi.org/10.1016/j.ctcp.2015.12.007

Siringoringo, H. E. (2018). Faktor-raktor yang berhubungan dengan robekan jalan lahir 
Ni Wayan Noviani, Ni Wayan Sukma Adnyani

pada ibu bersalin di RS Bhayangkara Palembang tahun 2017. Masker Medika, 6(2), 548-553.

Yohanna, W. S. (2018). Hubungan senam yoga prenatal dengan lamanya proses persalinan kala II pada ibu bersalin di BPS Nengah Sriniati
Kabupaten Mesuji tahun 2017. Midwifery Journal: Jurnal Kebidanan UM Mataram, 3(1), 30-33. https://doi.org/10.31764/ mj.v3i1.122 